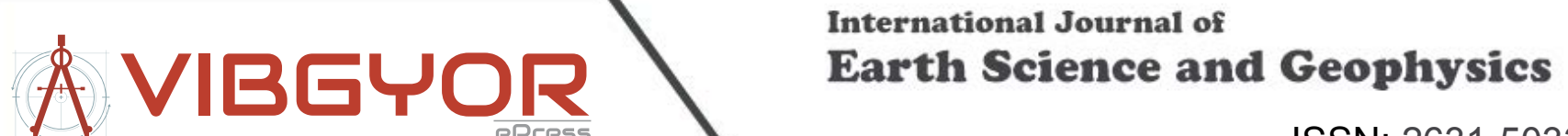

\section{Seismic and Gravity Evidence for Methane-Hydrate Systems in the Central Aleutian Basin}

\author{
Elizabeth A. Yankovsky*, Darrell A. Terry and Camelia C. Knapp \\ Department of Earth and Ocean Sciences, University of South Carolina, USA
}

\begin{abstract}
In this study, we analyze newly acquired seismic and gravity data sets (MGL1111) from the central Aleutian Basin of the Bering Sea to substantiate the hypothesis first proposed by Scholl and Cooper (1978) that methane plumes and associated gas hydrates are responsible for the regional seismic anomalies. These anomalies, known as VAMP (Velocity-AMPlitude anomaly) structures, were first discovered in this region in the 1970s. They are characterized by velocity pull-ups and associated push-downs in the seismic horizons. We present a comparison of near-offset, single channel seismic sections and processed shipboard gravimeter data from several of the fifteen lines of MGL1111. Results show prominent and ubiquitous VAMP structures throughout the seismic data. Remarkably, we find these VAMPs to correlate with significant lows in gravitational acceleration values- supporting the hypothesis of large volumes of methane hydrates being present. For the past several decades marine gas hydrates have been studied intensely under the assumption that deep ocean basins lack the methane necessary to generate gas hydrates. On the contrary, our findings support the assertion that the Aleutian Basin may contain globally significant volumes of methane in gaseous and hydrate form; this merits a rethinking of whether these systems are more common than previously anticipated.

Keywords

Gas hydrates, Aleutian basin, Gravity, Seismic analysis
\end{abstract}

\section{Introduction}

Marine gas hydrates have been the subject of intensive study since their discovery in the 1960s [1]. Gas hydrates are defined as solid icelike structures composed of a cage of water molecules surrounding a methane (or other gas) molecule that are stable only under certain thermobaric conditions [2-4]. Although deep ocean basins are known to have the appropriate temperature and pressure conditions for hosting methane hydrate systems, observational evidence of such systems has been primarily focused along continental margins within shallow sediments $[4,5]$. The expectation over the past several decades has thus been that deep ocean basins generally lack a sufficient source of methane and cannot generate gas hydrates.

The Aleutian Basin, however, may contradict this assertion. The basin is enclosed between the Aleutian Arc and Beringian Margin, resulting in impoundment of terrigenous organic sediment that over time may serve as a methane source for producing methane hydrates. The Aleutian Basin is largely composed of flat-lying and undisturbed sediments delivered to the area since the late Mesozoic [6]. These sediments coupled with the simple pancake geology, moderately high heat flow, and enclosed nature of the region are all factors that may account for significant amounts of methane and formation of gas hydrates.
Exploration in the Aleutian Basin began with the review of U.S. naval data in the 1960s and has expanded to include significant and extensive seismic data collections, site observations during the Ocean Drilling Program, and sonar surveys of the ocean floor [7]. In the early 1970s seismic evidence from the region led to the discovery of VAMP (Velocity-AMPlitude anomaly) structures characterized by velocity pull-ups and push-downs in the seismic horizons. According to a previous interpretation of this data by Scholl and Cooper [6], these anomalies may be indicative of methane plumes and/or the presence of gas hydrate formations. Furthermore, in 2009 three IODP sites were drilled along the Beringian Margin of the Bering Sea as part of Expedition 323 [8]. The sediment cores were found to vigorously release methane gas as they warmed, implying dissociation of pore-space methane hydrate [8,9]. Here, we analyze previously unpublished seismic and gravity data sets (MGL1111), acquired in 2011 for the U.S. Extended Continental Shelf Project in the central Aleutian Basin of the Bering Sea. We substantiate Scholl and Cooper's original hypothesis that the VAMPs are a result of methane gas and gas hydrates.

\section{Geologic Setting}

The deep waters of the Bering Sea are divided into three

${ }^{*}$ Corresponding author: Elizabeth A. Yankovsky, Department of Earth and Ocean Sciences, University of South Carolina, Columbia, SC 29208 USA, E-mail: eyankovsky@gmail.com

Received: August 08, 2015: Accepted: September 04, 2015: Published: September 07, 2015

Copyright: (c) 2015 Yankovsky EA. This is an open-access article distributed under the terms of the Creative Commons Attribution License, which permits unrestricted use, distribution, and reproduction in any medium, provided the original author and source are credited. 


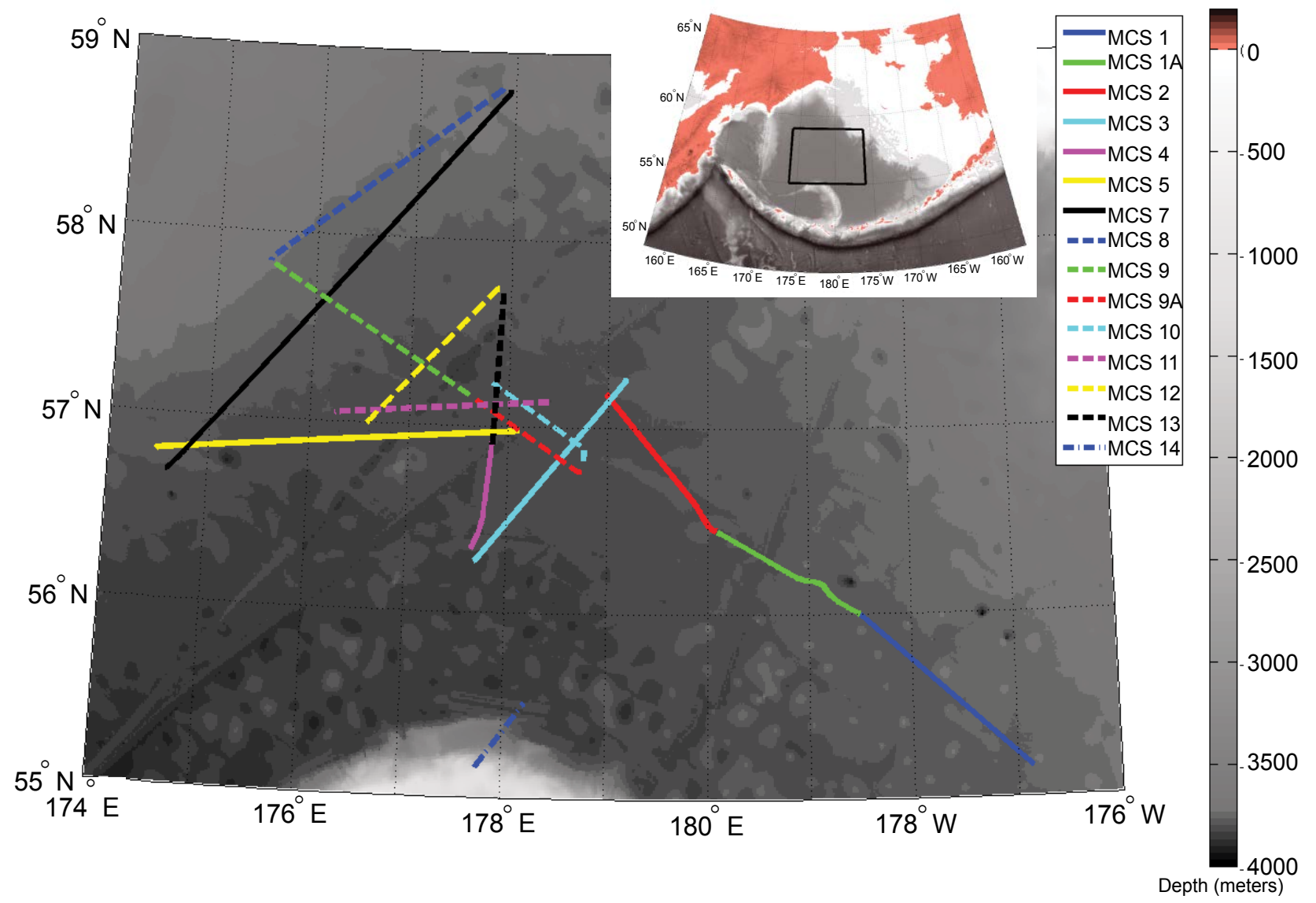

Figure 1: Bathymetric map of the central Aleutian Basin with tracks for the 2011 seismic lines. Bathymetry, update V15.1, courtesy of the Global Topography Project, University of California at San Diego; MGL1111 tracks courtesy of U. S. Geological Survey and Marine Geoscience Data System, LDEO, Columbia University.

physiographic areas: the Aleutian, Bowers, and Komandorsky Basins [10]. The three deep basins are separated by two aseismic ridges- Bowers Ridge, north of the Aleutian Arc, and Shirshov Ridge, extending from the Siberian mainland. The Aleutian Basin is located in the abyssal (depths greater than 3000 meters) portion of the Bering Sea just west of the Bering continental shelf. Primarily Cenozoic (65 Ma- present) sediments 2 to 9 kilometers thick are confined behind an outer island arc, the Aleutian Ridge. Apart from the great thickness of the overlying sedimentary section, the regional geologic and geophysical data indicate an underlying oceanic crustal structure. This suggests that the area was a part of the North Pacific Ocean until the late Mesozoic, 60 - $70 \mathrm{Ma}[10]$.

The Kula Plate, which split from the old Farallon plate about 80 $\mathrm{Ma}$, formed a large portion of the North Pacific Ocean bottom prior to $60 \mathrm{Ma}$. During this period the Kula plate was subducting beneath Kamchatka and the present day Beringian Margin. At 55-56 Ma the development of the Aleutian Ridge fractured the oceanic Kula plate, diverting subduction to the Aleutian Arc and leaving behind a segment of oceanic crust north of the newly formed ridge. Bowers and Shirshov Ridge may have also begun to develop at this time [10]. Since then, terrigenous and pelagic sediments have steadily accumulated in the area leading to a section of remarkably flat-lying, undisturbed sedimentary layers. When compared to other extensively studied oceanic basins, such as the geologically complex Gulf of Mexico, the sedimentary structure of the central Aleutian Basin thus stands out as "remarkably unremarkable".

\section{Thermal Environment}

According to Cooper et al. [10], the observed heat flow values in the Aleutian Basin are moderately high, with an average value of $1.44 \pm 0.22 \mathrm{microcal} / \mathrm{cm}^{2} / \mathrm{s}$. The regional geothermal gradient is also substantial, at $58^{\circ} \mathrm{C} / \mathrm{km}$. This is sufficient to reach the onset of thermogenic hydrocarbon generation $\left(50\right.$ to $\left.100^{\circ} \mathrm{C}\right)$ at fairly shallow sub-bottom depths of 0.9 to $1.8 \mathrm{~km}[10,11]$. Furthermore, based on applying temperature versus age and depth curves for known oil and gas producing basins, the generation of hydrocarbons in the central Aleutian Basin is predicted to occur in horizons as young as the early Miocene, 18 to $23 \mathrm{Ma}$ [10]. In other words, appropriate thermal conditions for biogenic and thermogenic degradation of organic matter leading to methane hydrate formation are ubiquitous throughout the basin. Due to the great water depth, seasonal changes in the sub-bottom thermal environment are believed to be negligible.

\section{Seismic Data}

We analyze a new seismic data set acquired in August 2011 aboard the R/V Marcus G. Langseth (Columbia University LDEO) in the central Aleutian Basin. Figure 1 shows ship tracks for the fifteen multi-channel seismic lines comprising MGL1111. An 8000 meter array of hydrophone receivers consisting of 636 channels at 12.5 meter spacing was utilized. The source was an air gun array consisting of forty guns with a $6600 \mathrm{in}^{3}$ total volume, fired at 2000 psi every 50 meters.

Shown in figure 2 are near-offset and far-offset single channel seismic sections connected to a sample shot gather, for line MCS09A. The $y$-axis shows signal two-way travel time, starting just above the water bottom. In the seismic sections, the $\mathrm{x}$-axis is shot gather number and in the shot gather, it is channel number. Normal move out (NMO) has not been applied, but the corresponding times between near and far offset can be identified by examining the shot gather. For display purposes we applied a wide band pass filter $(12.5$ to $125 \mathrm{~Hz})$ 

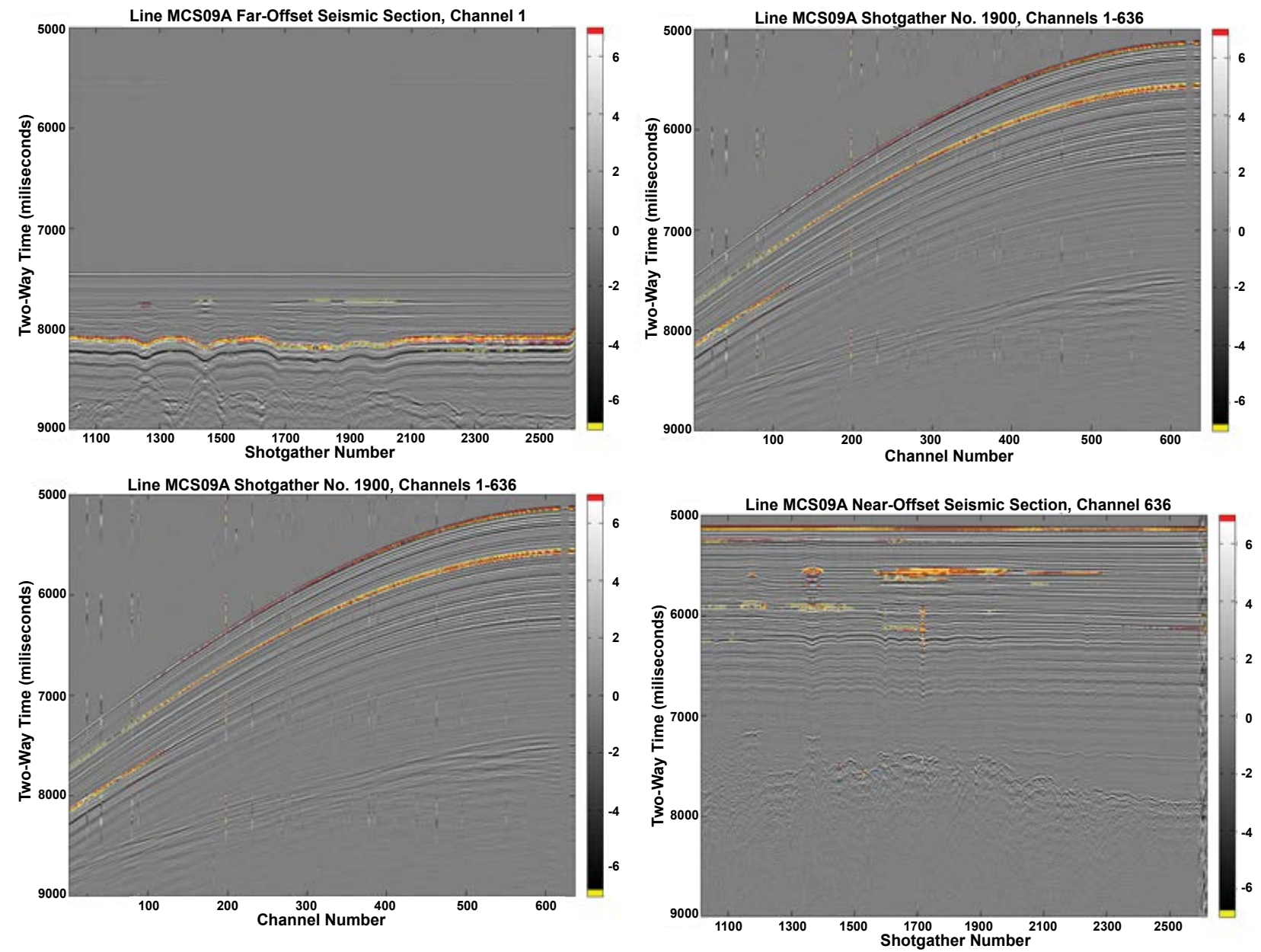

Figure 2: A complete view of line MCS09A. Shown in the upper left is the far-offset (channel 1), single channel seismic section. Shown in the bottom right is the near-offset (channel 636) seismic section. Beside each seismic section is shot gather 1900, which shows data for each of the channels (1-636) at shot point 1900. The $y$-axis in all images displays two-way signal travel-time in milliseconds, ranging from 5000 to $9000 \mathrm{~ms}$. The $\mathrm{x}$-axis in the seismic sections shows shot gather number; shot spacing is 50 meters, so overall distance covered in these sections is about 80 kilometers. For the shot gather, $x$-axis is channel number (1-636). The color bar is a linear grayscale representing signal amplitude, with extreme positive values and negative values colored in red and yellow, respectively.

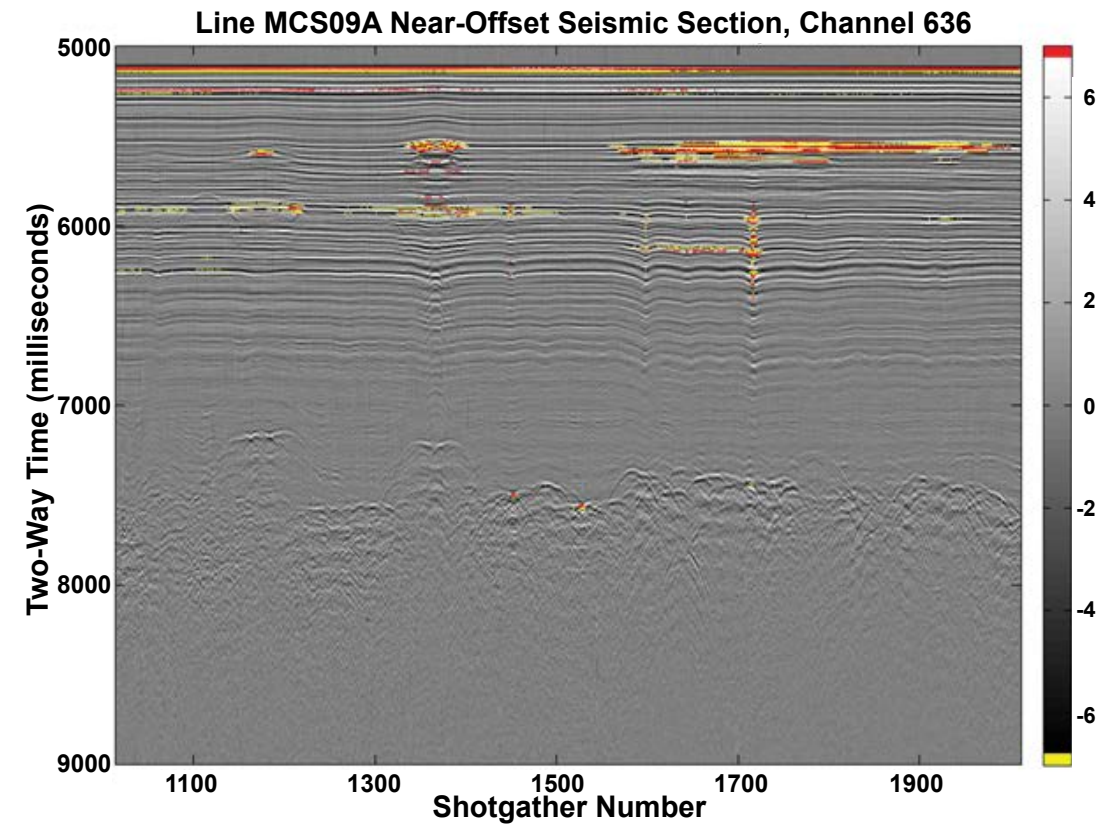

Figure 3: An enhanced view of the VAMP structures shown in the near-offset seismic section of figure 2, showing only shot gather numbers 1000 to 2000. 
to remove cable noise. A linear gray scale clipped at amplitudes of \pm 7 best defines the layering; yellow and red represent negative and positive clippings (respectively).

Examining the near-offset seismic section (Figure 2, lower right), several classic VAMP structures analogous to those first identified by Scholl and Cooper [6] are evident, most notably at shot gather numbers 1150 and 1350. Figure 3 is an enhanced view of these VAMP structures, showing only shot gather numbers 1000 to 2000 .

Generally, VAMP structures are characterized by a column of seismic push-downs and associated shallower pull-ups. The pushdowns are hypothesized to be caused by lower-velocity methane gas dissolved in the fluid-filled porous sediments $[6,7,12]$. This buoyant fluid rises through the porous medium until it reaches the lower limits of the gas hydrate stability zone, where the lower temperature and pressure conditions cause condensation into a solid gas hydrate. A very strong bottom simulating reflector (BSR) is often visible at this limit due to reflections from the presence of methane gas. This gas hydrate BSR, or GH-BSR, is typically identifiable in seismic records either because it parallels the bottom surface or cross-cuts the geological structure. In the central Aleutian Basin, the GH-BSR is estimated to lie at a sediment depth of 450 meters [12].The pull-ups attributed to solid gas hydrates extend for about 100 meters above the GH-BSR while push-downs are generally observed for hundreds of meters beneath the GH-BSR $[6,12]$.

(a)

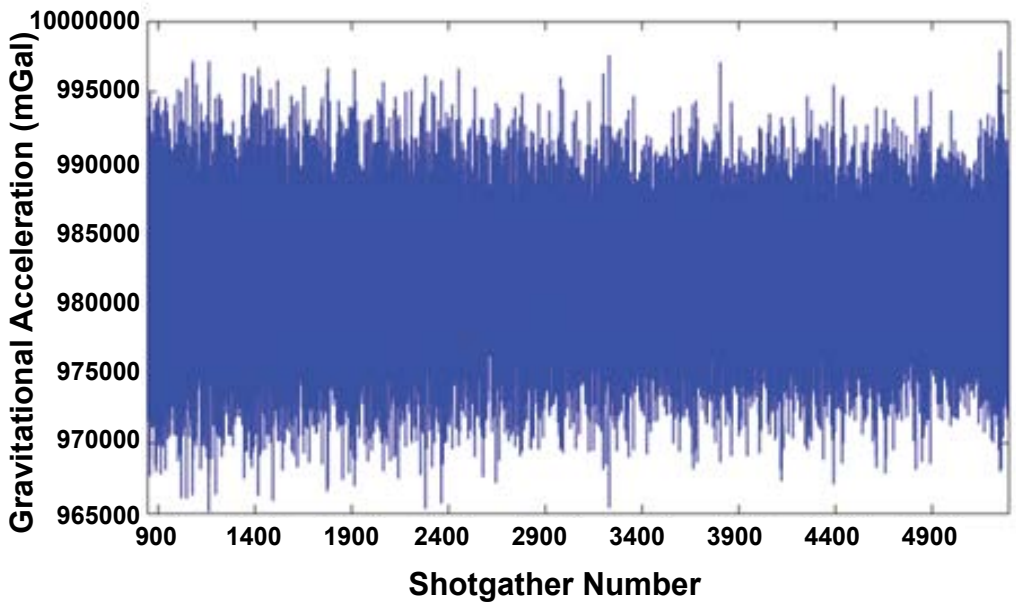

(b)

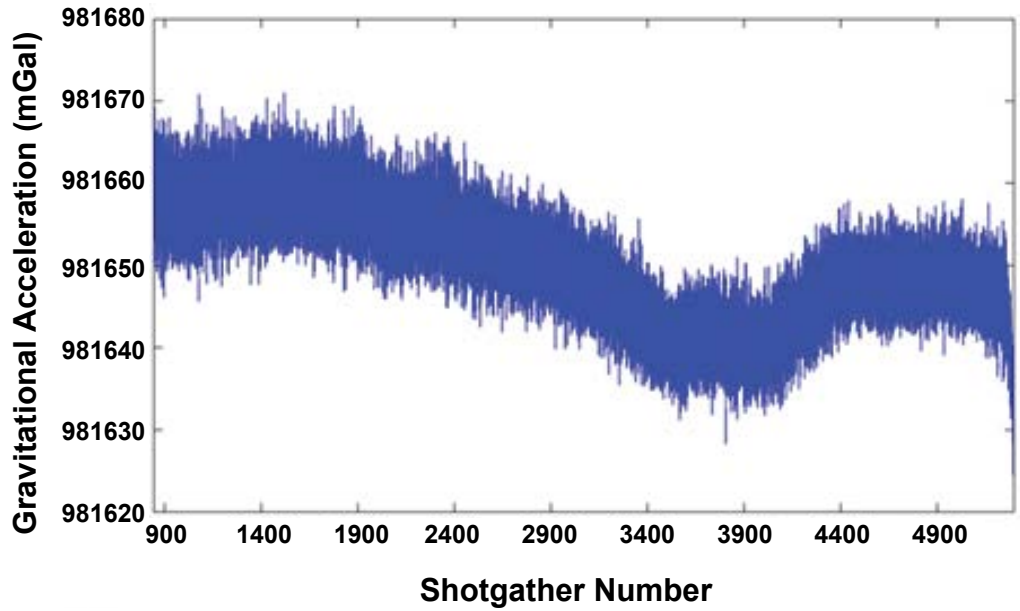

(c)

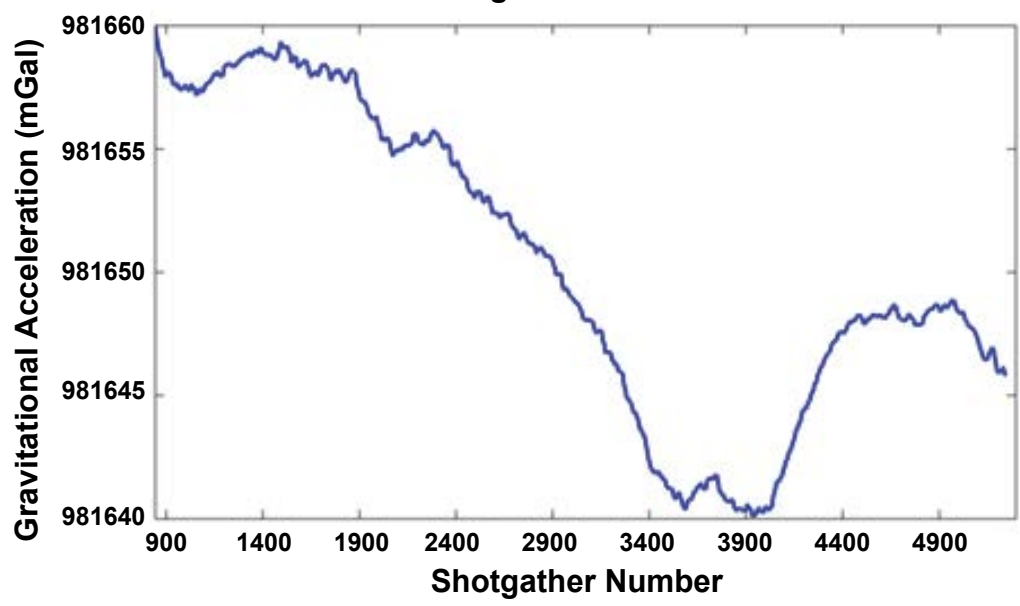

Figure 4: (a-c). Shown are the steps in processing gravity data, (a) shows raw data, (b) is after application of a Gaussian filter, and (c) is after subsequent application of a Median filter. 
In the MCS09A near-channel seismic section (Figure 2, lower right, and Figure 3), the GH-BSR appears around $5600 \mathrm{~ms}$. It is particularly continuous and strong between shot gathers 1600 and 2300, where several methane chimneys are also present. A second BSR is evident at $6300 \mathrm{~ms}$ - this is diagenetic boundary known as the CT-BSR. At a sub-bottom depth of about 600 meters, the alteration (through silica transformation) of water-rich biogenic opal A into cryptocrystalline opal CT produces a roughly $50 \%$ drop in porosity. This transition manifests itself in seismic data as the CT-BSR [13]. We identified the CT-BSR by examining the high grazing angle, far-offset seismic section (Figure 2, upper left). In this plot, the CTBSR is evident just below $8000 \mathrm{~ms}$, which if traced in the adjacent shot gather, indeed corresponds to about $6300 \mathrm{~ms}$ in the near-offset seismic section.

The VAMP structures at shot gathers 1150 and 1350 in the nearoffset section exhibit the characteristic seismic pull-ups above the GH-BSR and push-downs below, extending to an apparent basement at $7500-8000 \mathrm{~ms}$. Laterally, the structures are about $2-3 \mathrm{~km}$ in diameter and appear to exhibit semi-periodicity in their distribution.

According to Scholl and Cooper [6], there are three primary stratigraphic sections overlying the igneous basement. The uppermost unit occupies sub-bottom depths of 0-375 meters and consists of turbidite-bearing beds of diatom clay. The middle unit occurs at depths of 375-615 meters and consists of semi-indurated strata of diatom clay. The lowest unit is made up of mudstone and thin carbonate layers and extends from 615 meters to the basement (2 to $4 \mathrm{~km}$ sub-bottom depth) [6]. Seismic data indicates that the upper limit of the VAMPs typically occurs at/just beneath the upper unit of turbidite beds.

Similarly to Scholl and Cooper [6], we observed that VAMPs correlate with apparent basement highs. These basement highs potentially correspond to structural peaks of the basaltic basement, mud volcanoes, or acoustic scattering due to the presence of gas. Looking closer at the apparent basement in figure 3, one can see a discontinuity and the basement seems to partially disappear beneath the VAMPs. The uncertainty regarding basement structure served as motivation to process and analyze gravity data collected along the seismic lines. We wanted to identify whether apparent basement highs would lead to higher gravitational acceleration values or the opposite- that the large amount of gas potentially present within the VAMPs would lower gravity even in the presence of the potential basement highs.

\section{Gravity Data Processing}

Gravity data was collected using a Bell Aerospace BGM-3 Marine Gravity Meter System at 1 second intervals along each of the seismic lines of MGL1111. Processing was performed according to Bell and Watts [14]. The BGM-3 gravimeter system works by suspending a mass
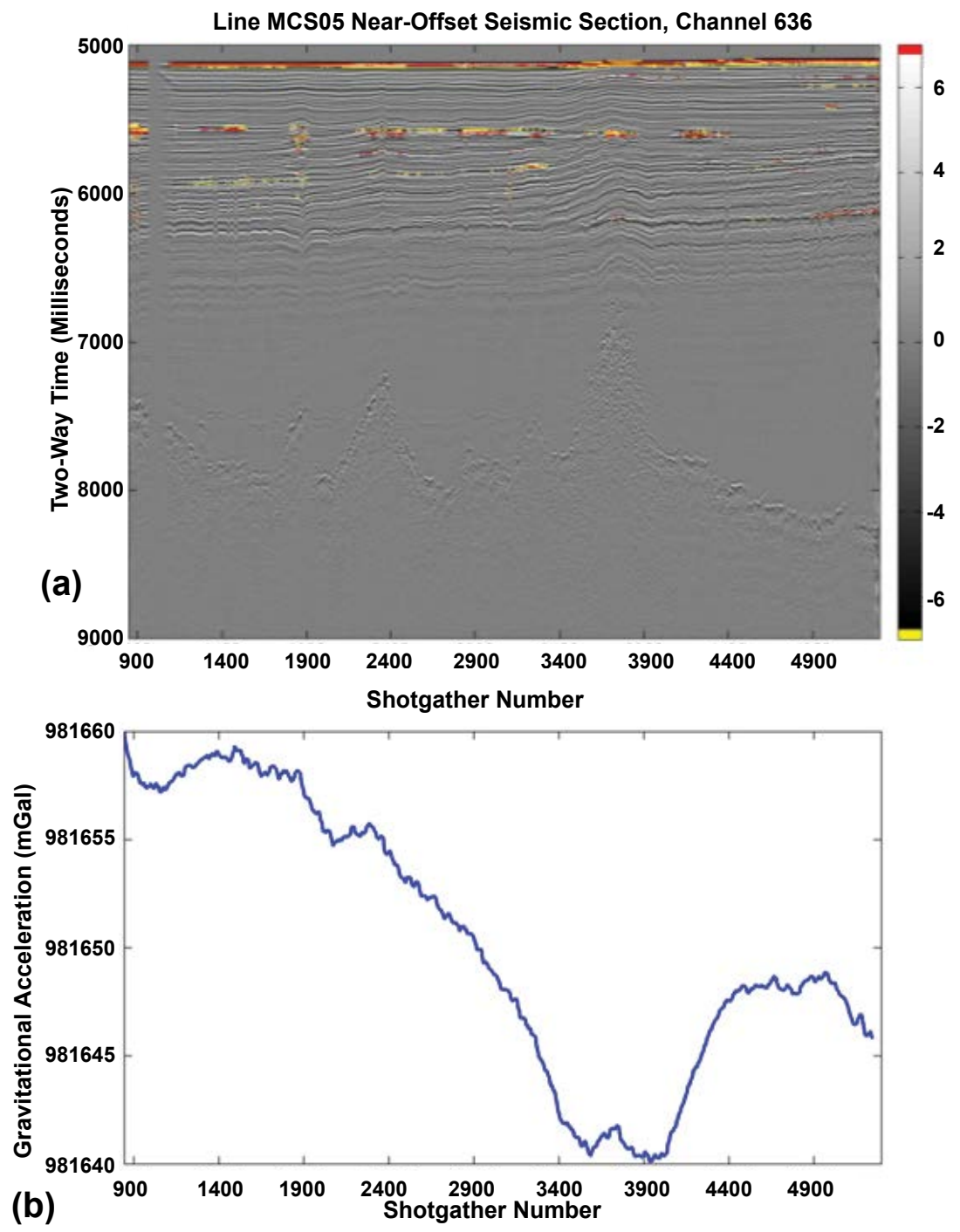

Figure 5: (a-b) Shown is the single channel, near-offset seismic section for line MSC05 and the corresponding processed gravity data. 
wrapped in a coil vertically between two permanent magnets. The mass is balanced by the force of gravity and the electromagnetic force induced in the coil. The current in the coil varies proportionally to changes in vertical acceleration. Output from the accelerometer is a current proportional to vertical acceleration in the range of 0 to $200 \mathrm{Gal}$ [14].

In the first step of processing we merged the navigation data, seismic line locations, and corresponding gravity measurements. We then multiplied the gravity measurements by a conversion factor of 4.9938 and added a bias of $855,613 \mathrm{mGal}$ to obtain a raw gravitational acceleration measurement in $\mathrm{mGal}\left(1 \mathrm{~m} / \mathrm{s}^{2}=100,000 \mathrm{mGal}=100\right.$ $\mathrm{Gal})$. This is shown for line MCS05 in figure 4a. We then applied a Gaussian filter with a 60 second window (Figure $4 \mathrm{~b}$ ), and a Median filter with a 480 second window (Figure 4c). The parameters for these filters are based on suggestions in Bell and Watts [14]. No gravity corrections were applied due to the flat nature of the bottom and the instrument being at sea level. Finally, we checked cross-over errors between gravity measurements taken at the same location but at different times (on different, but crossing seismic lines). The errors were all relatively small, ranging from 1-30 mGal.

\section{Seismic and Gravity Analysis}

Here, we compare near-offset seismic sections to the corresponding processed gravity measurements for three seismic lines: MCS05, MCS03, and MCS11. In MCS05 (Figure 5) the GHBSR again lies at $5600 \mathrm{~ms}$ and the CT-BSR at $6300 \mathrm{~ms}$. As in MCS09A, we observe a semi-periodic appearance of VAMP structures with associated apparent basement highs beneath. VAMPs are generally marked by a particularly high-amplitude signal at the GH-BSR, but individually exhibit variations in their seismic response.

For instance, the VAMP structure at shot gather 1800 is fairly classic- pull-ups are present above the GH-BSR and the pushdowns below extend to the apparent basement peak at $7500 \mathrm{~ms}$. The narrower methane chimneys evident between shot gathers 2700-3400 also exhibit such classic behavior.

However, the VAMP structure centered at shot gather 2300 exhibits pull-ups even below the GH-BSR. This character is even more pronounced around shot gather 3700 , where pull-ups extend from the apparent basement to the surface. This may be due to the geological arching of the sediment layers that is swamping the push-down signal of existing gas. One should also note that in spite of arching in the geologic layers, the GH-BSR remains horizontal as expected.

The corresponding gravity data for MCS05 shows a remarkable trend. At the VAMP structure locations there are significant decreases (up to $10 \mathrm{mGal}$ ) in gravitational acceleration indicative of regional mass deficits. Even around shot gather 3700, where there is a very strong apparent basement peak with pull-ups extending to the surface, the gravitational acceleration values plummet. This serves as convincing support of the hypothesis of a large volume of gas being present within the VAMPs. Further evidence is provided
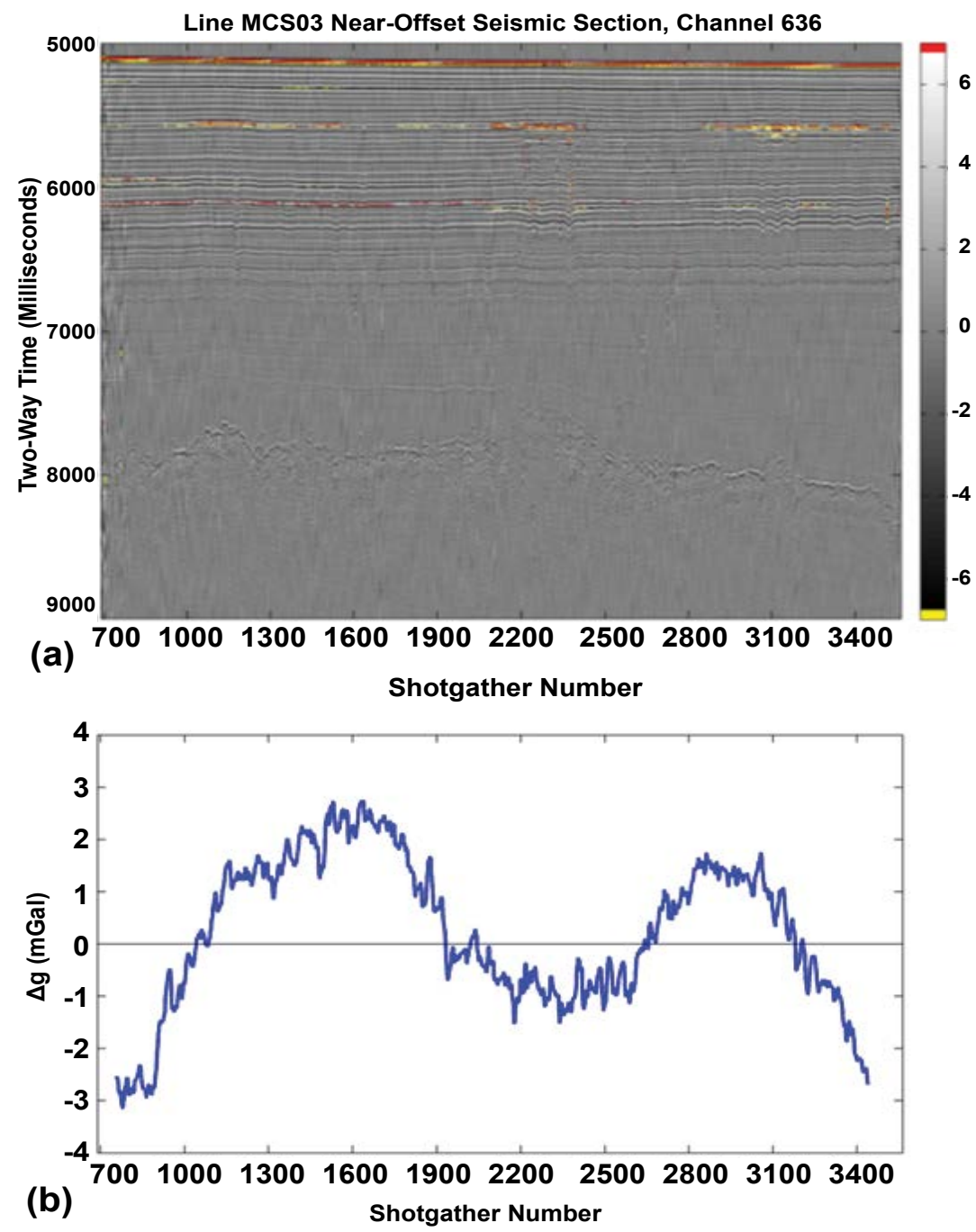

Figure 6: (a-b) Shown is the single channel, near-offset seismic section for line MSC03 and the corresponding processed gravity data. For this line we removed the regional trend of decreasing gravitational acceleration from $981,680 \mathrm{mGal}$ to $981,590 \mathrm{mGal}$ along the line in order to better visualize local effects. Thus, gravity is plotted as deviation from the linear regression line rather than as an absolute value. 
by the methane-rich core samples obtained by IODP Expedition 323 and by the regional thermal conditions favorable to thermogenic methane generation $[8,9]$. Figure 6 shows seismic data for line MCS03 with corresponding gravity data. For this line we removed the regional trend to better visualize local effects. Except for the edges the trend was linear, so we plotted the data as a deviation from the linear regression line. There is a prominent decrease in gravitational acceleration between shot gathers 2000-2500, again corresponding to an apparent basement high with two small, classic VAMP structures and a strong GH-BSR signature. The apparent basement high has a much flatter and indistinct character than the peaks in line MCS05. Line 11 (Figure 7) shows a similar trend to lines MCS03 and MCS05, with two VAMP structures: one between shot gathers 1300-1700 and the other between shot gathers 2700-3000. These VAMPs also correlate with apparent basement highs and decreased gravitational acceleration values.

Thus, based on analyzing several seismic lines and corresponding gravity data of MGL1111, we found a strong correlation between observed VAMP structures and lows in gravitation acceleration values. This indicates a regional mass deficit at VAMP structure locations, in spite of the peaks in the apparent basement. For a basaltic basement, peaks should produce a mass surplus rather than deficit.

We also confirm the correlation of VAMPs with apparent basement highs, first noted by Scholl and Cooper [6] and further examined by Rearic et al. [15]. In the latter paper, the authors attempted to quantify this correlation and found that only $28 \%$ of VAMPs occur over basement highs, while $57 \%$ occur over flat or depressed basement ( $15 \%$ were unresolvable). Nonetheless, they suggest that the topography of the apparent basement may well influence VAMP structure genesis [15].

Unfortunately, the identity of the apparent basement remains elusive. The seismic signature is often noisy and unclear beneath VAMPs. One hypothesis is that the apparent basement is a structural peak of the basaltic basement. However, the mass deficit suggests large volumes of gas. The structural highs may be attributed to physical phenomenology such as a thermal or fluid-flow boundary or acoustic interference.

\section{Conclusions}

To conclude our analysis, we note that there are extensive and prominent VAMP structures present throughout most of the lines, with a semi-periodic spacing of roughly $10-20 \mathrm{~km}$. The overall trend is that the VAMPs correspond to apparent basement highs and significant decreases in gravitational acceleration values. If the hypothesis of methane hydrates being responsible for the VAMPs is correct, we find it quite remarkable that the amount of gas within the VAMPs is presumably so high as to produce a clear signature in the gravity data. We remain unsure of the identity of the apparent basement, but believe a plausible interpretation is that the peaks are a result of gas being generated in the lowest-layer sediments overlying the basaltic basement, and the peaks represent acoustic scattering.

In order to gain insight into the structure of the basement, we plan to continue our investigation with pre-stack velocity, spectral, and seismic-Q analysis. We will also perform conventional multichannel processing.
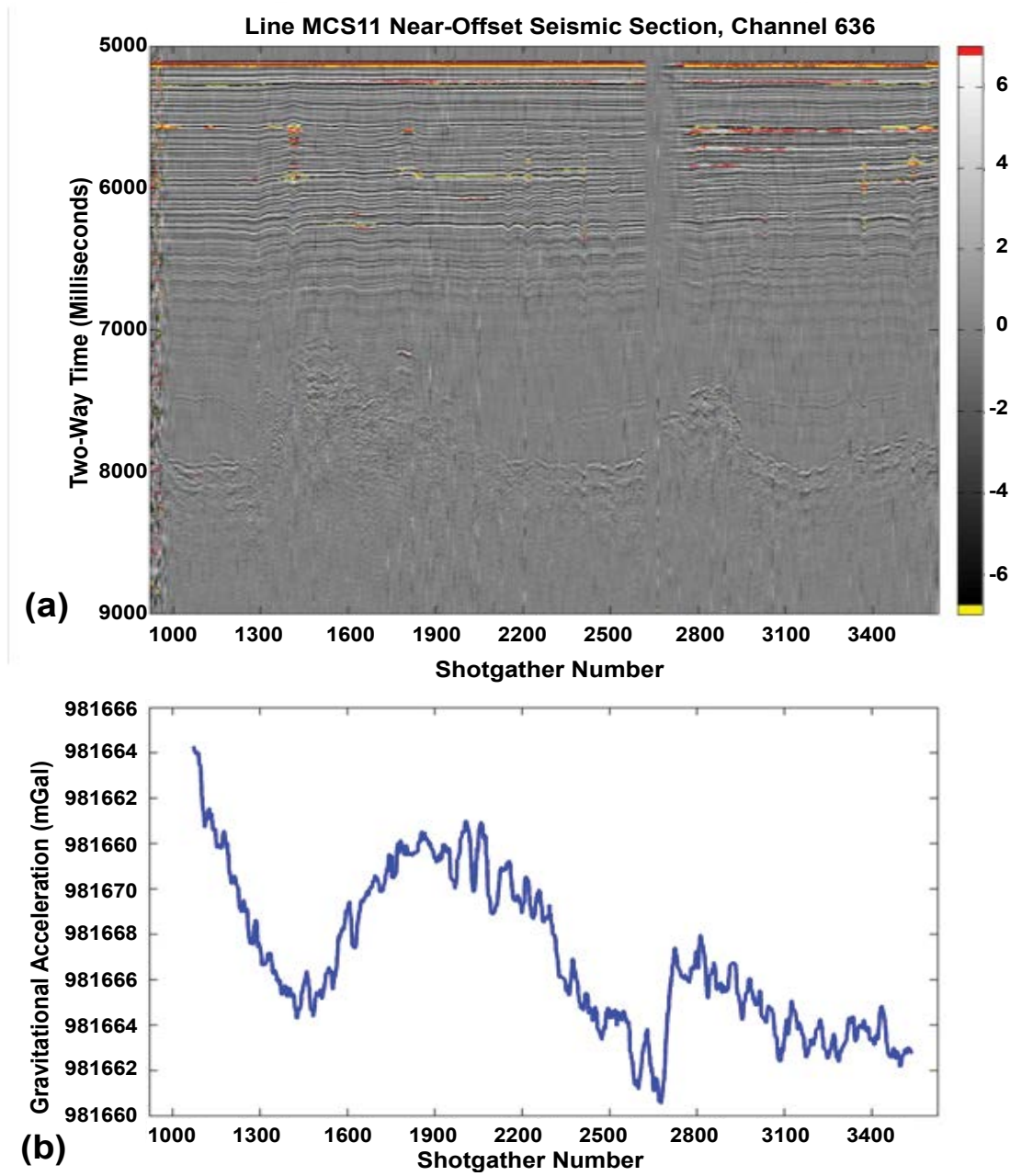

Figure 7: (a-b) Shown is the single channel, near-offset seismic section for line MSC11 and the corresponding processed gravity data. 


\section{Acknowledgements}

The MGL1111 data sets were made available to us though the courtesies of Ginger Barth, U.S. Geological Survey, and Warren Wood, Naval Research Laboratory, and the assistance of Rose Anne Weissel, Marine Geosciences Data System, LDEO, Columbia University. We also thank Halliburton for the Landmark Software grant to the Department of Earth and Ocean Sciences at the University of South Carolina.

\section{References}

1. Makogon YF (1966) Specialties of Exploitation of the Natural Gas Hydrate Fields in Permafrost Conditions. Ministry of Gas Industry, Moscow.

2. Trehu AM, Ruppel C, Holland M, Dickens GR, Torres ME, et al. (2006) Gas Hydrates in Marine Sediments: Lessons from Scientific Ocean Drilling. Oceanography 19: 124-142.

3. Sloan ED (1997) Gas Hydrate Tutorial. Center for Hydrate Research, Colorado School of Mines, USA.

4. Sloan ED (1998) Molecular Structures and Similarities. In: Clathrate Hydrates of Natural Gases: Second Edition, Revised and Expanded. Marcel Dekker, USA.

5. Hyndman RD, Davis EE (1992) A Mechanism for the Formation of Methane Hydrate and Seafloor Bottom-Simulating Reflectors by Vertical Fluid Expulsion. Journal of Geophysical Research 97: 7025-7041.

6. Scholl DW, Cooper AK (1978) VAMPs- possible hydrocarbon-bearing structures in Bering Sea basin. Am Assoc Pet Geol Bull 62: 2481-2488.

7. Cooper AK, Scholl DW, Marlow MS (1987) Structural framework, sedimentary sequences, and hydrocarbon potential of the Aleutian and Bowers Basins, Bering Sea. In: Scholl DW, Grantz A, Vedder JG Geology and Resource Potential of the Continental Margin of Western North America and Adjacent
Ocean Basins, Beaufort Sea to Baja California. Circum-Pacific Council for Energy and Mineral Resources, Earth Science Series, Volume 6: 473-502.

8. Expedition 323 Scientists, 2010. Bering Sea paleoceanography: PliocenePleistocene paleoceangraphy and climate history of the Bering Sea. IODP Prel Rept 323.

9. Scholl DW, Wood WT, Barth GA, Childs JR (2012) The Bering Sea Basin New drilling and geophysical observations and evidence for an important contribution of thermogenic methane to interstitial deposits of methane hydrate. Eleventh International Conference on Gas in Marine Sediments, Nice, France, 4-7 September 2012, France.

10. Cooper AK, Scholl DW, Marlow MS, Childs JR, Redden GD, et al. (1979) Hydrocarbon potential of Aleutian Basin, Bering Sea. Am Assoc Pet Geol Bull 63: 2070-2087.

11. Schoell M (1988) Multiple Origins of Methane in the Earth. Chemical Geology 71: $1-10$.

12. Scholl DW, Hart PE (1992) Velocity and amplitude structures on seismic reflection records- Possible massive gas hydrate deposits and underlying gas accumulations in the Bering Sea Basin. In: Howell DG, The Future of Energy Gases, USGS Prof Pap 1570, 331-351.

13. Scholl DW, Barth GA, Childs JR (2009) Why hydrate-linked velocity-anomaly structures are common in the Bering Sea Basin: A hypothesis, In: Collett $T$, Johnson A, Knapp C, Boswell R Natural Gas Hydrates- Energy Resource Potential and Associated Geologic Hazards, AAPG Memoir 89: 308-323.

14. Bell RE, Watts AB (1986) Evaluation of the BGM-3 Sea Gravity Meter System Onboard R/V Conrad. Geophysics 51: 1480-1493.

15. Rearic DM, Williams SR, Carson PR, Hall RK (1988) Acoustic evidence for gas-charged sediment in the abyssal Aleutian Basin, Bering Sea, Alaska. Dept of the Interior, US Geological Survey, Open-File Report 88-677. 